\title{
Variáveis morfogênicas de milheto (Pennisetum americanum) mantido em duas alturas de pastejo
}

\author{
Morphogenic variables of pearl millet (Pennisetum americanum) in \\ two grazing height
}

\author{
Carlos Eduardo Nogueira Martins ${ }^{1}$ Fernando Luiz Ferreira de Quadros ${ }^{2}$ \\ Duilio Guerra Bandinelli ${ }^{3}$ Luiz Felipe Cattani Simões ${ }^{4}$ \\ Mircon Giovani Kloss ${ }^{5}$ Marta Gomes da Rocha ${ }^{2}$
}

\section{RESUMO}

Este trabalho foi realizado com o objetivo de avaliar a resposta morfogênica de milheto (Pennisetum americanum) ao uso de duas alturas de manejo da pastagem. Utilizou-se a técnica de afilhos marcados para se monitorarem as variáveis em estudo. Os tratamentos propostos foram pastagem de milheto manejada a alturas médias de $20-30$ e $40-50 \mathrm{~cm}$. As variáveis determinadas foram: filocrono, números médios de folhas em elongação e folhas verdes por afilho, taxas de aparecimento, desfolha, elongação e senescência foliar. O tratamento com altura média de 20-30cm apresentou maior taxa de senescência e maior número de folhas elongando, respectivamente no primeiro e segundo períodos de avaliação. No tratamento com altura de $40-50 \mathrm{~cm}$, foi observado um maior número de folhas senescendo, maior comprimento final de folhas e filocrono, respectivamente no primeiro e segundo períodos. A taxa de desfolha diferiu entre tratamentos, sendo mais elevada na menor altura de plantas, em ambos os períodos. A taxa de aparecimento de folhas foi superior no segundo período na menor altura de plantas, influenciada pela menor altura dos afilhos neste período. As respostas morfogênicas podem ser atribuídas às modificações impostas pelos tratamentos à estrutura da pastagem. A utilização de uma altura de pastejo entre $20-30 \mathrm{~cm}$ mantem uma maior proporção de folhas na pastagem.

Palavras-chave: filocrono, taxa de aparecimento de folhas, taxa de elongação foliar, taxa de senescência foliar, freqüência de desfolha.

\begin{abstract}
This work evaluated the morphogenic response of pearl millet (Pennisetum americanum) to two heights of pasture management. Marked tillers were used to check the variables being studied. Proposed treatments were average heights of 20-30 and 40-50cm. The variables evaluated were: phyllochron; average numbers of elongated leaves and of green leaves per tiller; appearance, defoliation, elongation and leaf senescence rates. The treatment with average height of 20$30 \mathrm{~cm}$ presented greater senescence rate and greater number of elongating leaves, respectively, in the first and second periods of evaluation. In the treatment with height of $40-50 \mathrm{~cm}$ a greater number of senescent leaves, greater final leaf length and phyllochron was observed, respectively in the first and second periods. The rate of leaf defoliation differed between treatments, being higher in the lower height of plants, in both periods. The rate of leaf appearance was higher in the second period in the lower height of plants, influenced by the lower height of the tiller in this period. The morphogenic responses can be assigned to changes in pasture structure imposed by the treatments. The use of a grazing height around $20-30 \mathrm{~cm}$ maintained a higher proportion of leaves in the pasture.
\end{abstract}

Key words: phyllochron, leaf appearance rate, leaf elongation rate, leaf senescence rate, defoliation frequency.

\footnotetext{
${ }^{1}$ Aluno de Graduação em Zootecnia, Universidade Federal de Santa Maria (UFSM), Santa Maria-RS. Bolsista de Iniciação Científica/Fundação de Amparo à Pesquisa do Estado do Rio Grande do Sul (FAPERGS), E-mail: cenmartins@ig.com.br ${ }^{2}$ Engenheiro Agrônomo, Doutor, Professor Adjunto, Departamento de Zootecnia, UFSM, 97105-900, E-mail: fquadros@ccr.ufsm.br. Autor para correspondência.

${ }^{3}$ Engenheiro Agrônomo, Aluno do Curso de Pós-graduação em Zootecnia, UFSM. Bolsista da Coordenação de Aperfeiçoamento de Pessoal de Ensino Superior (CAPES). E-mail: bandlli@zipmail.com.br

${ }^{4}$ Aluno de Graduação em Agronomia, Zootecnia, UFSM.
} 


\section{INTRODUÇÃO}

A pecuária brasileira está estreitamente ligada à exploração de pastagens naturais e cultivadas, e a alta produtividade das gramíneas forrageiras se torna um dos principais fatores responsáveis pelo sucesso desta atividade. Gramíneas anuais de estação quente, como o milheto (Pennisetum americanum), têm função assegurada em sistemas de pastejo que visem alta produtividade de forragem e animal por área. Além da grande adaptação às condições climáticas da região Sul, esta espécie é capaz de produzir grande quantidade de forragem de alta qualidade em curto espaço de tempo (CASTRO, 2002). Dessa forma, o milheto pode ser recomendado como um contribuinte ativo de produção de forragem, na maioria dos programas de produção animal do Sul do Brasil (MARASCHIN, 1979). Esta elevada produção de massa seca (MS) faz com que se deva buscar um manejo adequado da pastagem, tanto sob pastejo contínuo quanto rotativo, com uma carga animal capaz de consumir o crescimento da forragem, evitando com isso o acúmulo de material velho na planta, além de favorecer a emissão constante de novos afilhos por parte da planta (QUADROS et al., 2003).

O principal objetivo do manejo da pastagem é conciliar as exigências do animal e a necessidade de manter o potencial produtivo das plantas pastejadas (HODGSON, 1990). Este mesmo autor definiu a altura da pastagem como a altura média das lâminas foliares. Relacionando a altura da pastagem e a massa de forragem com o crescimento de borregas, WEBBY \& PENGELLY (1986) verificaram que o parâmetro altura constitui-se como um bom indicador do nível de massa de forragem durante as estações do ano. A altura da superfície das lâminas foliares, a densidade, a massa de forragem e a quantidade de folhas presentes na pastagem são as características que mais afetam a produção de forragem e o desempenho animal (HODGSON, 1990). A forte correlação entre altura e quantidade de alimento disponível permitiu o estabelecimento de guias de manejo de pastagem usando a altura como referência, dada a sua facilidade de compreensão, análise e aplicação (CASTRO, 2002).

Um entendimento adequado dos efeitos de variação nas condições da pastagem sobre o desempenho, tanto da planta, como do animal, e da sensibilidade destes à interface do manejo, pôde ser atingido somente em estudos baseados no controle e manipulação de características específicas da pastagem (HODGSON, 1985). O animal ajusta seu comportamento em pastejo de acordo com a oferta da fração preferida da forragem e a sua distribuição espacial no relvado (MANNETJE \& EBERSOHN, 1980).

Em um dossel vegetativo, a morfogênese de plantas pode ser descrita com base na taxa de aparecimento e de alongamento de folhas e tempo (duração) de vida da folha (LEMAIRE \& CHAPMAN, 1996). A combinação destas três variáveis morfogenéticas determina as três principais características estruturais das pastagens: tamanho da folha, densidade de afilhos e número de folhas vivas por afilho (CRUZ \& BOVAL, 1999). Os processos de alongamento de folhas e hastes, dependentes do genoma e das condições edáficas, demandam carbono como substrato energético e estrutural, que são ofertados pelo conjunto de fotoassimilados oriundos da fotossíntese (GASTAL \& DURAND, 2000) e mobilização de reservas orgânicas da planta. A altura do pasto é uma estratégia de manejo que pode alterar esse conjunto de fotoassimilados, em termos de produção e partição e, portanto, as características morfogênicas e estruturais da planta. Diferentes alturas de manejo proporcionam, também, diferenças na estrutura da pastagem e, conseqüentemente, na morfogênese da planta, uma vez que alteram a dinâmica do processo de desfolhação efetuado pelo animal (PONTES et al., 2003).

No pastejo contínuo, relações estreitas entre variáveis de condição da pastagem, tais como, altura e densidade, e o comportamento de pastejo dos animais determinam a freqüência e a intensidade de desfolhação de plantas individuais (LEMAIRE, 1997). O mesmo autor cita que uma planta, quando sofre qualquer evento de desfolha, tem sua fisiologia profundamente afetada por esta remoção e pela freqüência de sua realização na mesma unidade morfológica.

Considerou-se a hipótese de que a altura de pastejo condiciona aspectos morfogênicos, estruturais e a freqüência de desfolha de milheto. $\mathrm{O}$ objetivo deste trabalho foi avaliar a resposta morfogênica e estrutural de milheto, pastejado a duas alturas.

\section{MATERIAL E MÉTODOS}

O experimento foi conduzido na UFSM, situada na região fisiográfica denominada Depressão Central do Rio Grande do Sul, no período de novembro de 2001 a abril de 2002. Esta região situa-se a 2943’ de latitude Sul, 5342’ de longitude Oeste, com altitude média de 95 metros acima do nível do mar e clima subtropical úmido (Cfa). O solo da área experimental é classificado como ARGISSOLO VERMELHO Distrófico Arênico (EMBRAPA, 1999). 
A área experimental, de 5,4 hectares (ha), foi dividida em seis potreiros de aproximadamente 0,7 ha, $\mathrm{e}$ um potreiro com cerca de 1,2ha para permanência dos animais reguladores. Os herbicidas glifosate e 2,4-D foram aplicados nas dosagens de três e $0,8 \mathrm{~L} \mathrm{ha}{ }^{-1}$, respectivamente, para controle da vegetação. A primeira semeadura direta ocorreu no dia 14/11/01, utilizando $35 \mathrm{~kg} \mathrm{ha}^{-1}$ de sementes de milheto em linha. Uma forte chuva, que ocorreu após a semeadura, causou selamento superficial do solo que prejudicou, seriamente, a emergência. Foi necessária uma nova semeadura a lanço no dia 26/11/01, utilizando-se uma densidade de sementes de $30 \mathrm{~kg} \mathrm{ha}^{-1}$. A adubação de base ocorreu por ocasião da primeira semeadura, utilizando-se 280 kgha-1 da fórmula 5-20-20 (NPK). Em cobertura, utilizaram-se $130 \mathrm{~kg} \mathrm{ha}^{-1}$ de $\mathrm{N}$, na forma de uréia, divididos em três aplicações, nos dias 23/01, 11/02 e 21/ 03/02.

Os tratamentos propostos foram duas alturas médias: 20-30 e 40-50cm, com três repetições por tratamento. A altura média da pastagem no período foi de 28,50 e $46,39 \mathrm{~cm}$, respectivamente para os tratamentos denominados de $20-30$ e $40-50 \mathrm{~cm}$.

O método de pastejo foi contínuo, com taxa de lotação variável, conforme metodologia proposta por MOTT \& LUCAS (1952). Foram utilizadas novilhas de corte da raça Charolês cruzadas com Nelore, com início do pastejo em 30/12/01. A carga animal foi ajustada a cada 14 dias conforme a altura da pastagem pretendida, a qual era medida com régua no momento da avaliação da massa de forragem. Para determinar a altura média da pastagem, foram tomados aleatoriamente três pontos amostrais por potreiro, sendo a altura da pastagem determinada pelo ponto médio de curvatura das folhas no dossel. A massa de forragem foi determinada de acordo com a metodologia proposta por WILM et al. (1944), utilizando-se um quadro de $0,25 \mathrm{~m}^{2}$ de área, sendo avaliadas aleatoriamente 20 amostras por potreiro.

Para avaliação das variáveis morfogênicas foram marcados, com fios telefônicos coloridos, 60 afilhos por potreiro. A primeira folha de cada afilho e as pastejadas foram marcadas com corretor ortográfico à base de água, para servir de referência em avaliações posteriores (primeira) ou para ser identificada nova desfolha em avaliação subseqüente. As avaliações foram realizadas em intervalos consecutivos de três a quatro dias. Após seis medições, novas plantas foram marcadas e avaliadas, mantendo-se o mesmo intervalo. Os dois períodos de avaliação ocorreram de 03/01 a 21/01 e de 28/01 a 15/02/02.

As medidas realizadas consistiram em medir o comprimento da porção verde de cada folha, a partir do ponto de intersecção da lâmina foliar com o colmo (folhas elongadas, ou seja, com a lígula exposta) até a extremidade de seu ápice. Folhas em elongação foram medidas a partir da lígula da última folha elongada. A altura média do afilho foi medida partindo-se de sua base, ao nível do solo, até a altura atingida por suas folhas estendidas. A condição em que se encontrava a folha: elongada, em elongação, senescendo, desfolhada ou totalmente senescida era registrada em planilha. As variáveis determinadas foram: taxas de aparecimento, elongação, desfolha e senescência foliar, números médios de folhas em elongação e folhas verdes por afilho, filocrono e duração de vida das folhas.

Para o cálculo das taxas de elongação e senescência, utilizou-se o valor médio de elongação e senescência das folhas por afilho, que não foram pastejadas no período amostral, dividida pelo valor de filocrono, dos respectivos períodos avaliados. O filocrono foi calculado através de uma regressão entre o valor da soma térmica acumulada durante os intervalos de avaliação do período e o número médio de folhas dos afilhos em cada intervalo considerado. O filocrono é o valor inverso do coeficiente angular desta regressão, expresso em graus-dia (GD). O cálculo da soma térmica diária acumulada baseou-se na equação: $\left(\left(\mathrm{T}_{\mathrm{Mx}}^{\mathrm{o}}+\mathrm{T}_{{ }_{\mathrm{Mn}}}\right) 2^{-1}\right)-10^{\circ} \mathrm{C}$, onde $\mathrm{T}^{\mathrm{o}}{ }_{\mathrm{Mx}}$ =temperatura máxima, $\mathrm{T}^{\mathrm{o}}{ }_{\mathrm{Mn}}=$ temperatura mínima, $10^{\circ} \mathrm{C}$ é a temperatura base de crescimento da planta (WESTPHALEN, 1975).

Para a taxa de aparecimento, foi utilizado o número médio de novas folhas surgidas durante o período de avaliação, dividido pelo número de dias do período. A taxa de desfolha foi calculada a partir dos registros nos afilhos, sendo expressa em valor percentual médio. Através do produto do número de folhas verdes por afilho pelo filocrono obteve-se a duração de vida das folhas. Folhas verdes foram consideradas aquelas que não apresentavam senescência nem haviam sido pastejadas no período de avaliação. O percentual de lâminas foliares e de colmos foi determinado por separação manual, de três amostras coletadas por potreiro, num quadro de $1 \mathrm{~m}^{2}$ de área, segundo metodologia proposta por STOBBS (1973). A relação folha/colmo foi determinada pela divisão do percentual destes componentes da pastagem.

O delineamento experimental utilizado foi o inteiramente casualizado, sendo que os valores médios das variáveis avaliadas dos 60 afilhos por repetição de área (potreiro), constituíram as unidades amostrais analisadas por período. As análises estatísticas utilizaram a rotina de testes de aleatorização do programa MULTIV (PILLAR, 1997), em nível de $6 \%$ de probabilidade de erro. 


\section{RESULTADOS E DISCUSSÃO}

Pode-se observar que houve diferença significativa na taxa de aparecimento foliar (Tabela 1) apenas no segundo período de avaliação, sendo as maiores taxas $(0,202$ folhas por dia) verificadas no tratamento de menor altura de plantas. Neste período, os intervalos médios para o aparecimento de uma nova folha foram de 4,95 e 5,55 dias, respectivamente para os tratamentos de 20-30 e 40-50cm de altura média da pastagem. No primeiro período, não houve diferença entre as taxas ou intervalos de aparecimento, sendo necessários na média dos tratamentos 9,13 dias para o aparecimento de uma nova folha. A justificativa para o fato, é que os afilhos selecionados para avaliação não apresentaram diferença significativa na sua altura média (Tabela 2), embora as alturas médias dos potreiros fossem diferentes. Os valores de taxa de aparecimento do segundo período são inferiores aos 7,3 dias observados por GONÇALVES \& QUADROS, (2003) no período de 20/02 a 08/03/01, no tratamento de pastagem de milheto sem suplementação.

A altura do dossel da pastagem pode influenciar a taxa de aparecimento foliar devido ao aumento do comprimento da bainha das folhas sucessivas de gramíneas cespitosas, havendo uma maior demora no surgimento das folhas acima do pseudocaule (LEMAIRE \& CHAPMAN, 1996). Esta influência foi observada no segundo período. Quando comparadas às alturas médias dos afilhos avaliados (Tabela 2), com a redução da altura média, houve uma redução considerável no número de dias necessários para o surgimento de uma nova folha, em ambos os tratamentos (Tabela 1).

A taxa de elongação foliar não diferiu entre tratamentos nos períodos avaliados. O

Tabela 1 - Taxas de aparecimento foliar (folhas por dia), elongação e senescência foliar (mm GD ${ }^{-1}$ afilho ${ }^{-1}$ ), desfolha (\% folhas desfolhadas afilho $^{-1}$ ), filocrono (GD), números médios de folhas elongando e folhas verdes por afilho e duração de vida das folhas (GD) em pastagem de milheto manejada em duas alturas.

\begin{tabular}{|c|c|c|}
\hline \multirow{2}{*}{ Altura da pastagem $(\mathrm{cm})$} & \multicolumn{2}{|c|}{ Períodos } \\
\hline & 03/01 a 21/01 & $28 / 01$ a $15 / 02$ \\
\hline & \multicolumn{2}{|c|}{ Taxa de aparecimento foliar (folhas por dia) } \\
\hline $20-30$ & 0,116 & $0,202 a^{*}$ \\
\hline \multirow{2}{*}{$40-50$} & 0,103 & $0,180 \mathrm{~b}$ \\
\hline & \multicolumn{2}{|c|}{ Taxa de elongação foliar $\left(\mathrm{mm} \mathrm{GD}^{-1}\right.$ afilho $\left.^{-1}\right)$} \\
\hline $20-30$ & 1,11 & 1,79 \\
\hline \multirow[t]{2}{*}{$40-50$} & 1,06 & 1,64 \\
\hline & \multicolumn{2}{|c|}{ Número médio de folhas elongando por afilho } \\
\hline $20-30$ & 2,55 & $2,72 \mathrm{a}$ \\
\hline \multirow[t]{2}{*}{$40-50$} & 2,46 & $2,61 \mathrm{~b}$ \\
\hline & \multicolumn{2}{|c|}{ Taxa de senescência foliar $\left(\mathrm{mm} \mathrm{GD}^{-1}\right.$ afilho $\left.^{-1}\right)$} \\
\hline $20-30$ & 0,790 a & 0,206 \\
\hline \multirow[t]{2}{*}{$40-50$} & $0,467 \mathrm{~b}$ & 0,265 \\
\hline & \multicolumn{2}{|c|}{ Taxa de desfolha (\% folhas desfolhadas afilho ${ }^{-1}$ ) } \\
\hline $20-30$ & 31,72 a & $32,98 \mathrm{a}$ \\
\hline \multirow[t]{2}{*}{$40-50$} & $23,28 \mathrm{~b}$ & $29,86 \mathrm{~b}$ \\
\hline & \multicolumn{2}{|c|}{ Filocrono (GD) } \\
\hline $20-30$ & 155,7 & $83,0 \mathrm{~b}$ \\
\hline \multirow[t]{2}{*}{$40-50$} & 184,6 & 97,2 a \\
\hline & \multicolumn{2}{|c|}{ Número médio de folhas verdes por afilho } \\
\hline $20-30$ & 5,63 a & 5,69 \\
\hline \multirow[t]{2}{*}{$40-50$} & $5,09 \mathrm{~b}$ & 5,69 \\
\hline & \multicolumn{2}{|c|}{ Duração de vida (GD) } \\
\hline $20-30$ & 876,6 b & $472,3 \mathrm{~b}$ \\
\hline $40-50$ & $939,6 \mathrm{a}$ & 553,1 a \\
\hline
\end{tabular}

* Medidas seguidas de letras distintas na coluna diferem estatisticamente entre si pelo teste de aleatorização, em nível de 6\% de probabilidade de erro.

Ciência Rural, v.35, n.1, jan-fev, 2005. 
Tabela 2 - Carga animal ( $\mathrm{kg} \mathrm{ha}^{-1}$ de PV), altura média de afilho (cm), porcentagens de folhas e colmos, precipitação pluviométrica (mm) e massa de forragem ( $\mathrm{kg} \mathrm{ha}^{-1}$ de MS) em pastagem de milheto manejada em duas alturas. Valores médios por período.

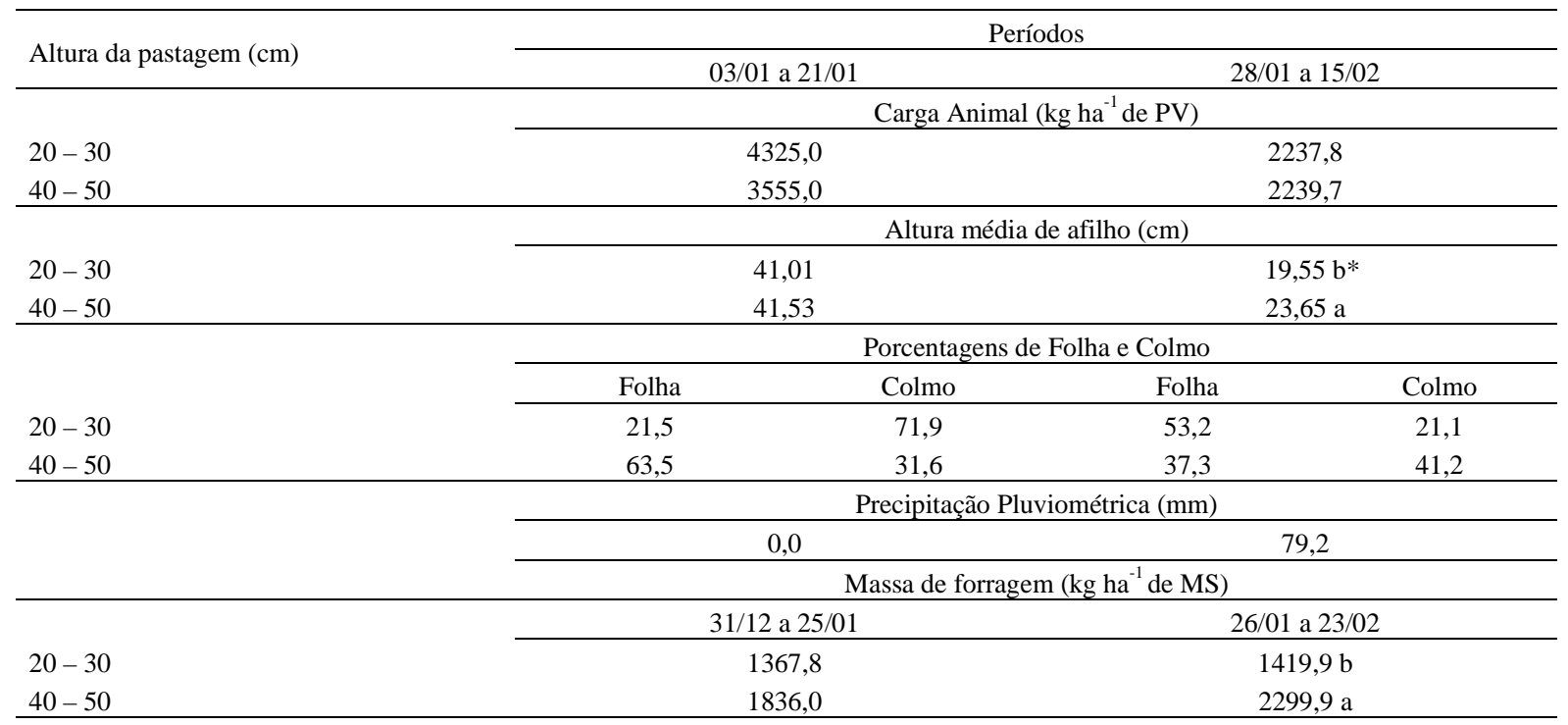

* Médias seguidas de letras distintas na coluna diferem estatisticamente entre si pelo teste de aleatorização, em nível de 6\% de probabilidade de erro.

aumento ocorrido do primeiro para o segundo período possivelmente foi devido principalmente ao déficit hídrico (Tabela 2) ocorrido em todo o primeiro período, o que não ocorreu no segundo. Esta variável apresenta maior resposta à disponibilidade de nutrientes (especialmente $\mathrm{N}$ ) (NABINGER, 1996), que foi semelhante entre os tratamentos. Os valores de elongação do segundo período (Tabela 1), na ordem crescente das alturas, correspondem a 31,2 e 28,6 $\mathrm{mm} \mathrm{dia}^{-1}$ afilho-1, valores superiores aos $27,5 \mathrm{~mm} \mathrm{dia}^{-1}$ afilho- $^{-1}$ observados por GONÇALVES \& QUADROS (2003) no período de 20/02 a 08/03/01, com $75 \mathrm{~kg} \mathrm{ha}^{-1}$ de $\mathrm{N}$ já aplicados.

O número médio de folhas elongando por afilho diferiu entre tratamentos apenas no segundo período, quando os tratamentos de $20-30$ e $40-50 \mathrm{~cm}$ apresentaram respectivamente 2,72 e 2,61 folhas elongando na média do período (Tabela 1). Com relação aos valores de filocrono calculados, observou-se menores valores para o tratamento de menor altura. A combinação destas duas variáveis, o número de folhas elongando e um menor intervalo para o surgimento de novas folhas, representam uma resposta da planta ao estresse ambiental sofrido no período anterior. Esse foi imposto pela combinação de uma carga superior em 770kg de peso vivo e ao déficit hídrico (Tabela 2). As condições favoráveis do segundo período, menor carga e maior precipitação, permitiram esta resposta morfogênica.
A taxa de senescência foliar apresentou diferença significativa entre tratamentos apenas no primeiro período, sendo a maior taxa verificada na menor altura de plantas. As plantas do tratamento de 20-30cm possuíam menor percentual de folhas (Tabela 2), o que provavelmente reduziu sua capacidade para extrair água do solo e, associado ao déficit hídrico, diminuiu a duração de vida das folhas. A duração de 939,6 GD encontrada nesse trabalho, para o tratamento de $40-50 \mathrm{~cm}$, foi superior ao valor de 327,0 GD observado por GONÇALVES \& QUADROS (2003), no período de 20/02 a 08/03/01, trabalhando com pastagem de milheto com altura média de $43,6 \mathrm{~cm}$.

Houve um aumento da relação folha/colmo para o tratamento de $20-30 \mathrm{~cm}$ no segundo período $(2,5)$ em relação ao primeiro $(0,3)$, conseqüência da redução na carga animal ou podendo ser uma resposta da planta emitindo novos afilhos. Conforme MOOJEN (1993), o aumento da carga animal na pastagem atua negativamente na relação folha/colmo. Já para o tratamento de $40-50 \mathrm{~cm}$, a relação folha/colmo diminuiu de 2,0 para 0,9 , pois à medida que a planta amadurece, devido à morte de afilhos e menor atividade dos meristemas, a relação folha/colmo decresce (HERINGER, 1995).

O número médio de folhas verdes diferiu apenas no primeiro período (Tabela 1). Segundo NABINGER (1996), o número de folhas verdes é uma característica genotípica, e relativamente constante, 
podendo as diferenças observadas serem conseqüência da amostragem. Os valores médios de folhas verdes observados (Tabela 1), para ambos os períodos e tratamentos são superiores as 4,2 folhas verdes observadas por GONÇALVES \& QUADROS, (2003) no período de 20/02 a 08/03/01.

A taxa de desfolha apresentou diferença significativa nos dois períodos de avaliação, sendo os maiores valores observados no tratamento de 20$30 \mathrm{~cm}$ de altura de plantas, em ambos os períodos. Esta diferença está consistente com a maior carga animal empregada no primeiro período, a qual foi $21,66 \%$ superior no tratamento $20-30 \mathrm{~cm}$ de altura de plantas (Tabela 2). Entretanto, a necessidade de redução da carga, no segundo período avaliado, para manter as alturas desejadas, não interferiu nessa taxa, devido à menor massa de forragem neste tratamento. Os valores de taxa de desfolha do segundo período são superiores aos observados por GONÇALVES \& QUADROS, (2003) em período próximo (20/02 a 08/03/01), utilizando uma carga média de 2236,6 $\mathrm{kg}_{\text {ha }}{ }^{-1}$ de $\mathrm{PV}$, que é semelhante àquela observada no segundo período.

\section{CONCLUSÕES}

A utilização de uma altura de pastejo entre 20-30cm provoca um aumento nas taxas de desfolha proporcionada pela manutenção de uma elevada carga animal. A resposta morfogênica das plantas é uma maior taxa de aparecimento de folhas, o que resulta em uma maior proporção de folhas na pastagem. As variáveis morfogênicas avaliadas, exceto a taxa de elongação, apresentam respostas às variações de estrutura da pastagem impostas pelos tratamentos, bem como às condições ambientais.

\section{REFERÊNCIAS BIBLIOGRÁFICAS}

CASTRO, C.R.C. Relações planta-animal em pastagem de milheto (Pennisetum americanum (l.) Leeke) manejada em diferentes alturas com bovinos. 2002. $185 \mathrm{f}$. Dissertação (Mestrado em Zootecnia) - Curso de Pós-graduação em Zootecnia, Universidade Federal do Rio Grande do Sul.

CRUZ, P.; BOVAL, M. Effect of nitrogen on some morphogenetical traits of temperate and tropical perennial forage grasses. In: SIMPÓSIO INTERNACIONAL GRASSLAND ECOPHYSIOLOGY AND GRAZING ECOLOGY, 1., 1999, Curitiba. Anais... Curitiba : UFPR, 1999. p.134-150.

EMBRAPA. Centro Nacional de Pesquisa Agropecuária. Sistema brasileiro de classificação de solos. Rio de Janeiro : EMBRAPA, 1999. 412p.

GASTAL, F.; DURAND, J. Effects of nitrogen and water supply on $\mathrm{N}$ and $\mathrm{C}$ fluxes and partitioning in defoliated swards.
In: LEMAIRE, G. et al. (Eds.). Grasslands ecophysiology and grazing ecology. Wallingford, UK : CAB INTERNATIONAL, 2000. p.15-39.

GONÇALVES, E.N.; QUADROS, F.L.F. Morfogênese de milheto (Pennisetum americanum (L.) Leeke) em pastejo com terneiras, recebendo ou não suplementação. Ciência Rural, Santa Maria, v.33, n.6, p.1123-1128, 2003.

HERINGER, I. Efeito de níveis de nitrogênio sobre a dinâmica de uma pastagem de milheto (Pennisetum americanum (L.) Leeke) sob pastejo. 1995. $183 \mathrm{f}$. Dissertação (Mestrado em Zootecnia) - Curso de Pós-graduação em Zootecnia, Universidade Federal de Santa Maria.

HODGSON, J. Grazing management: science into practice. Longman scientific and technical. London : Longman Group, UK, 1990. 203p.

HODGSON, J. The significance of sward characteristics in the management of temperate sown pastures. In: INTERNATIONAL GRASSLAND CONGRESS, 15., 1985, Kioto. Proceedings... Kioto: IGC, 1985. p.63-67.

LEMAIRE, G.; CHAPMAN, D. Tissue flows in grazed plants communities. In: HODGSON, J; ILLIUS, A.W. (Eds). The ecology and management of grazing systems. Wallingford, UK : CAB INTERNATIONAL, 1996. p.336 .

LEMAIRE, G. The physiology of grass growth under grazing: Tissue turn-over. In: SIMPÓSIO INTERNACIONAL SOBRE PRODUÇÃO ANIMAL EM PASTEJO, 1997, Viçosa. Anais.... Viçosa : UFV, 1997. p.117-144.

MANNETJE, L't.; EBERSOHN, J.P. Relations between sward characteristics and animal production. Tropical Grassland, Sta Lucia, v.14, p.265-273, 1980.

MARASCHIN, G.E. Potencial produtivo de gramíneas forrageiras de verão no sul do Brasil. Lavoura Arrozeira, Porto Alegre, v.32, n.315, p.18-24, 1979.

MOOJEN, E.L. Avaliação de milheto (Pennisetum americanum (L.) Leeke) sob pastejo com níveis de nitrogênio. 1993. 39f. Tese (Acesso a Classe de Professor Titular) - Universidade Federal de Santa Maria.

MOTT, G.O.; LUCAS, H.L. The design conduct and interpretation of grazing trials on cultivated and improved pastures. In: INTERNATIONAL GRASSLAND CONGRESS, 6., 1952, Pensylvania. Proceedings... Pensylvania : State College, 1952. p.1380-1395.

NABINGER, C. Princípios de exploração intensiva de pastagens. In: PEIXOTO, A.M. et al. (Eds). PRODUÇÃO DE BOVInOS A PASTO, 13., 1996, Piracicaba. Anais... Piracicaba : FEALQ, 1996. p.15-96.

PILLAR, V.D.P. Multivariate exploratory analysis and randomization testing with MULTIV. Coenoses, Gorizia, v.12, p.145-148, 1997.

PONTES, L.S. et al. Variáveis morfogênicas e estruturais de azevém anual (Lolium multiflorum Lam.) manejado em diferentes alturas. Revista Brasileira de Zootecnia, Viçosa, v.32, n.4, p.814-820, 2003. 
QUADROS, F.L.F. et al. Variáveis morfogênicas de milheto sob diferentes alturas de manejo da pastagem. In: REUNIÃO ANUAL DA SOCIEDADE BRASILEIRA DE ZOOTECNIA, 40., 2003, Santa Maria. Anais... Santa Maria : SBZ, 2003. 1 CD.

STOBBS, T.H. The effect of plant structure on the intake of tropical pastures. II. Differences in sward structure, nutritive value and bite size of animal grazing Setaria anceps and Chloris gayana at various stages of growth. Australian Journal of Agricultural Research, Brisbane, v.28, p.824-829, 1973.

WEBBY, R.W.; PENGELLY, W.J. The use of pasture height as a predictor of feed level in north Island hill country. Proceedings of the New Zealand Grassland Association, Palmerston North, v.47, p.249-253, 1986.

WESTPHALEN, S.L. Forrageiras de clima tropical e subtropical - Zoneamento climático. In: ZONEAMENTO AGRÍCOLA, ESTUDOS BÁSICOS. 2., 1975, Porto Alegre. Anais... Porto Alegre : Governo do Estado do Rio Grande do Sul, 1975. p.26-32.

WILM, H.G. et al. Estimating forage yield by the doublesampling methods. Journal of American Society of Agronomy, New York, v.36, n.1, p.194-203, 1944. 